\title{
Recent Developments in Biological Water Oxidation
}

\author{
Nicholas Cox*, Montserrat Pérez-Navarro, Frank Neese, Wolfgang Lubitz and
}

Dimitrios A. Pantazis.

Max Planck Institute for Chemical Energy Conversion, Stiftstr. 34-36, D-45470

Mülheim an der Ruhr, Germany

Corresponding author*: Nicholas Cox, Tel: +49-208-306-3552; Email: nicholas.cox@cec.mpg.de

\begin{abstract}
Rapid progress has been made in the last five years towards resolution of the structure of nature's water splitting catalyst - a $\mathrm{Mn}_{4} \mathrm{O}_{5} \mathrm{Ca}$ cofactor embedded in Photosystem II - especially in the field of X-ray crystallography. In addition, recent magnetic resonance data have allowed the structure of the cofactor to be accessed in its last metastable intermediate state, prior to O-O bond formation. This activated form of the catalyst is geometrically similar to that seen by X-ray crystallography, which represents the resting state of the cofactor, but requires the coordination of an additional water molecule to the cofactor, rendering all $\mathrm{Mn}$ ions six coordinate. Importantly, it locates two water derived, Mn bound oxygen ligands in close proximity. It is these two oxygen ligands that likely form the product $\mathrm{O}_{2}$ molecule, as proposed earlier by quantum chemical modeling. Current views on the molecular level events that facilitate catalyst activation, that is, catalyst/substrate deprotonation, Mn oxidation and water molecule insertion are briefly described.
\end{abstract}

The structure of Nature's water splitting cofactor in its resting state: Crystallographic advances, including the introduction of free electron laser sources, have fundamentally altered the trajectory of research on the mechanism of biological water splitting [1]. These new methods have recently provided an atomic resolution crystal structure of the resting state of the catalyst. Specifically, the XFEL (X-ray free electron laser) structure: i) reproduces earlier EXAFS constraints (e.g. Mn-Mn distances) [2-4]; ii) clarifies the location of all oxygen bridges of the catalyst 
including the $\mathrm{O} 5$ bridge, which in earlier X-ray models (XRD) was placed in a chemically unprecedented bonding position; and iii) constrains the net oxidation state of the cofactor in the resting state (III,IV,IV,III) by resolving the Jahn-Teller axes of two Mn ${ }^{\text {III }}$ ions, Mn1 and Mn4 (see Fig. 1). This novel structure allows the information content of complementary spectroscopies to be fully realized and together these data now provide a solid basis for the development of robust chemical models throughout is entire catalytic cycle [5].
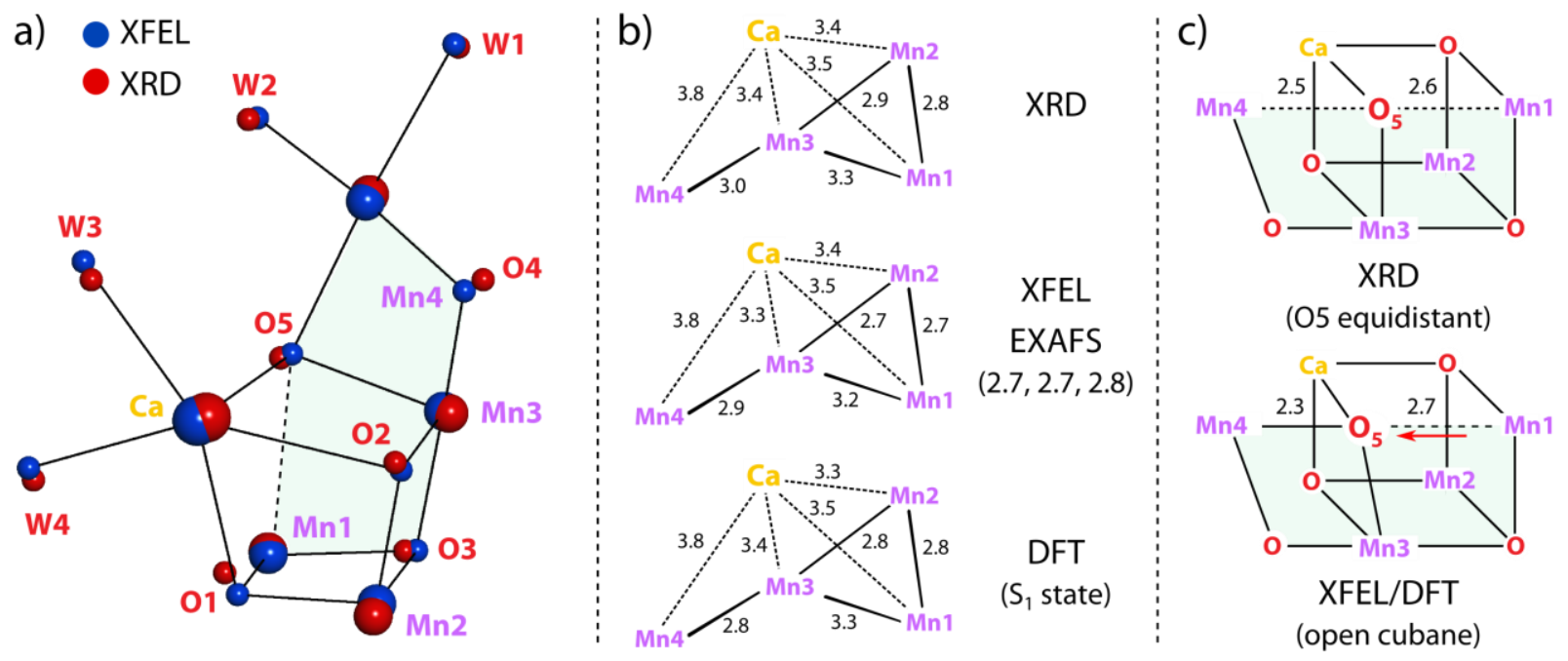

Fig. 1 A) Comparison of the new XFEL structure with the earlier synchrotron (XRD) structure of the $\mathrm{Mn}_{4} \mathrm{O}_{5} \mathrm{Ca}$ cofactor $[1,6]$. The cofactor resembles a distorted chair with the back of the chair shown by the light blue plane. The XFEL structure better reproduces EXAFS constraints [2,3] (panel B) and places O5 in a more chemically realistic position (panel $\mathrm{C}$ ), more in line with earlier chemical models [5,7-9]. The cofactor contains three coordinately saturated Mn ions (Mn2, Mn3 and Mn4) with a potential substrate binding site located at Mn1, the only five coordinate Mn ion. Mn4 and the $\mathrm{Ca}^{2+}$ ion both carry two water derived ligands. All remaining ligands are derived from the protein backbone and oxygen bridge network. Substitution of the $\mathrm{Ca}^{2+}$ ion with $\mathrm{Sr}^{2+}$ has little effect on the structure of the catalyst [10], in line with spectroscopic results [11].

Substrate binding and delivery to the catalyst: An understanding of the mechanism of biological water splitting is greatly aided by resolving what oxygen sites of the cofactor participate in the reaction $[12,13]$. Recent magnetic resonance data has implicated $\mathrm{O} 5$ as one of the two substrates owing to its fast exchange with bulk solvent water [14-16]. This is a unique property not seen for the other four bridges, or for oxygen bridges in simpler synthetic model systems [17-19]. The identity of the $2^{\text {nd }}$ substrate remains more contentious as it is unclear if it is bound in all intermediate states of the catalyst, or if bound in all states, whether its position changes during the cycle $[12,20]$. Water analogs such as ammonia and methanol provide a means to 
address this question by probing how the substrates first access the cofactor. Substrate access forms part of a larger debate on the dynamics of the solvent/substrate interface, namely how does the catalyst selectively activate two water solvent molecules (when it is surrounded by solvent water) and regulate solvent water access to the site of the catalyst, to avoid deleterious side products such as $\mathrm{H}_{2} \mathrm{O}_{2}$.

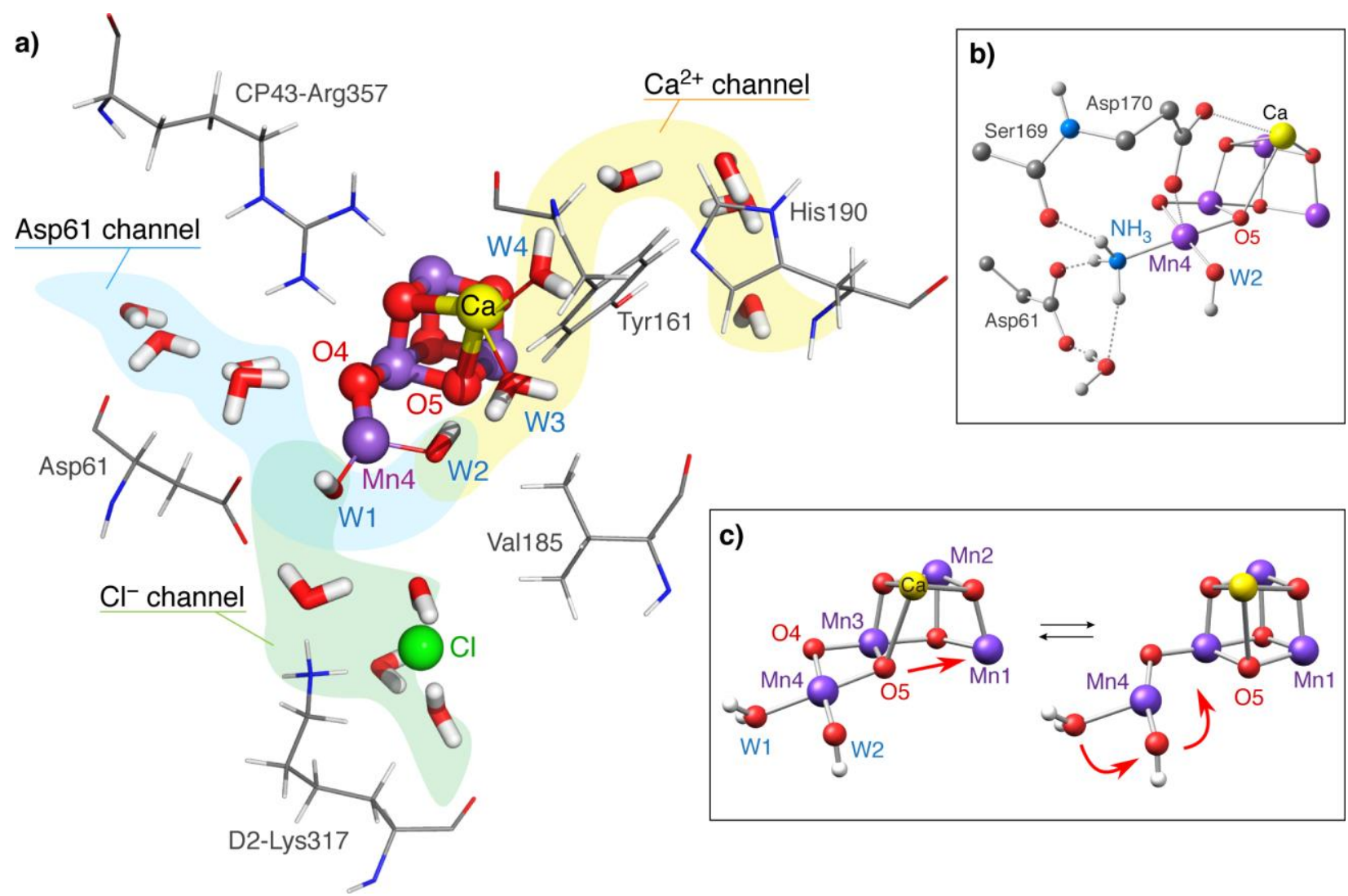

Fig. 2. a) Proposed access/egress channels to and from the $\mathrm{Mn}_{4} \mathrm{O}_{5} \mathrm{Ca}$ cofactor. b) Binding location of $\mathrm{NH}_{3}$ which displaces the water ligand (W1) to the outer manganese (Mn4). Its binding was used to identify the exchangeable oxygen bridge (O5) as ammonia binds near (trans to) the O5 bridge. c) Sequence of oxygen ligand movements that allow water binding to occur. Spectroscopic data support the cofactor being able to adopt open and closed cubane conformation, in support of this mechanism for substrate delivery $[9,21]$.

Although ammonia and methanol do not drastically alter the binding/exchange kinetics of the two substrates, their addition is associated with a decrease of the catalyst's efficiency under steady-state conditions suggesting that they hinder or interfere with substrate access to the site(s) of catalysis. The crystal structure identifies at least three water pathways leading towards/away from the cofactor: i) a channel which includes the $\mathrm{Ca}^{2+}$ ion and the redox active tyrosine residue (Yz); ii) a channel which includes the outer Mn4 and the Asp61 residue [1,6]; and iii) a similar channel which also includes the $\mathrm{Cl}^{-}$ion (Fig. 2a). The location of ammonia binding 
was recently deduced from chemical modelling [14,15,22] and mutagenesis [23], displacing the water ligand (W1) of the outer manganese (Mn4). The binding location of methanol, however, is less well defined, with one option placing it close to the site of ammonia binding and another favouring its binding at the $\mathrm{Ca}^{2+}$ [24]. Competitive binding of small molecules at/near the position of $\mathrm{W} 1$ indicate that the water channel associated with this site (Asp61 channel) is important for water delivery [25]. As a whole, these results favor that one of the water derived ligands of the Mn4 is the second substrate. Water binding via the Asp61 channel involves a rotation of the waters on the Mn4, initiated by the facile shift of the O5 bridge [9,21]. This cascade of structural rearrangements results in a five coordinate, trigonal bipyramidal $\mathrm{Mn}$ ion, shown in Fig. 2 [25]. Within this model water binding occurs on the back-face of the cofactor. As such the water molecule when first delivered is most likely not the substrate of the reaction - this is instead one of the existing water ligands (W2) - but form the substrate in the next catalytic cycle $[12,20]$.

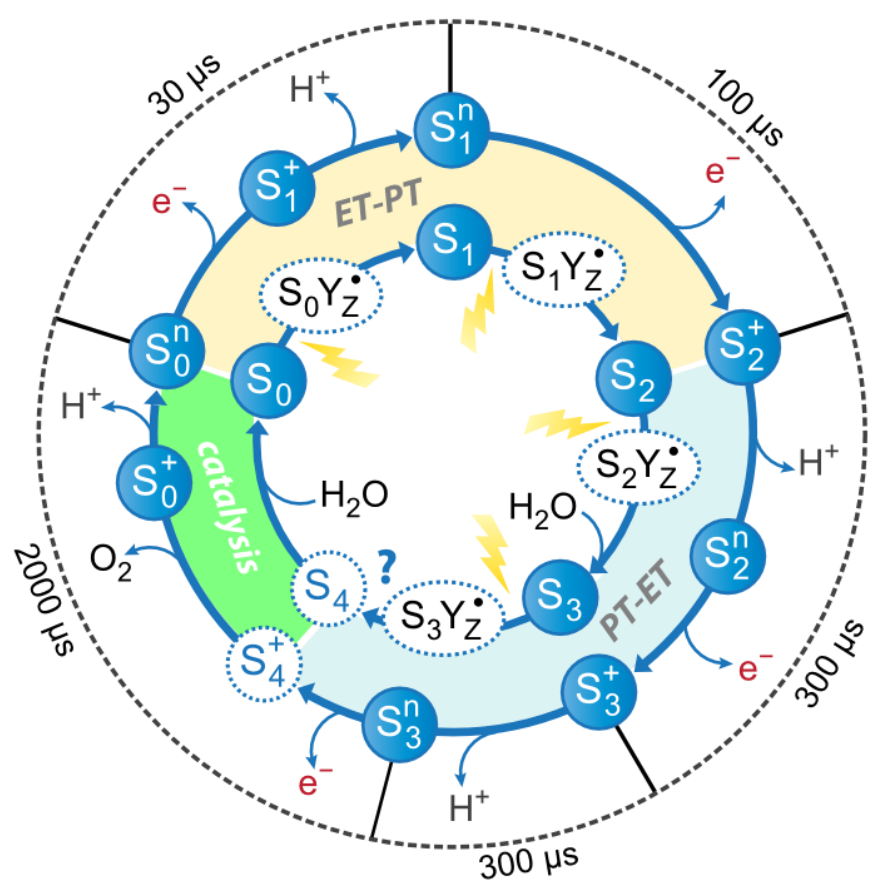

Fig. 3. Extended, nine intermediate $\mathrm{S}$-state cycle of the $\mathrm{Mn}_{4} \mathrm{O}_{5} \mathrm{Ca}$ cofactor, based on [26]. The cycle starts in the $\mathrm{S}_{0}{ }^{\mathrm{n}}$ state $\left(\mathrm{n}=\right.$ neutral) state. Up until the $\mathrm{S}_{2}{ }^{+}$, electron withdrawal precedes proton transfer $(E T-P T)$. Subsequently, generation of the $\mathrm{S}_{3}{ }^{+}$and $\mathrm{S}_{4}{ }^{+}$states requires first proton transfer then oxidation $(P T-E T) . \mathrm{S}_{0}{ }^{\mathrm{n}}$ is regenerated upon the spontaneous release of molecular oxygen and likely the binding and deprotonation of one of the substrates.

The structure of the activated catalyst - structural evolution during the S-state: It is well known that the cofactor cycles through a series of five intermediate states: $S_{0}$, 
$\mathrm{S}_{1}$ (dark stable), $\mathrm{S}_{2}, \mathrm{~S}_{3}$, and $\mathrm{S}_{4}$ where the subscript refers to the number of oxidizing equivalents stored by the cofactor. The $\mathrm{S}_{4}$ state spontaneously decays upon release of triplet $\mathrm{O}_{2}$ returning to the $\mathrm{S}_{0}$ state. Oxidation of the cofactor is driven by light excitation of the Photosystem II reaction center, via a redox active tyrosine residue $\left(Y_{Z}\right)$. Coupled with oxidation, protons are successively removed from the cofactor, to ensure its total charge/redox potential remains constant, termed redox tuning. As such the cycle can more accurately be described in terms of nine states which differ in terms of their net electron and proton count [26,27] (Fig. 3). An important observation is that at different points in the cycle the order in which electrons and protons are removed from the cofactor reverses; in the early $S$-state transitions (e.g. $S_{0}$ to $S_{1}$ ) electron transfer precedes proton transfer whereas in the late transitions (e.g. $S_{2}$ to $S_{3}$ ) proton transfer precedes electron transfer. As a consequence, $\mathrm{Y}_{\mathrm{Z}}$ can be though of having a dual role: i) it acts as an electron carrier; and ii) it promotes deprotonation of the catalyst which is presumably facilitated via the intervening H-bonding network.

The XFEL structure described above represents the resting state of the catalyst $\left(\mathrm{S}_{1}\right)$ [1], although it may contain some admixture of the $S_{0}$ state [5]. It is also thought to be a good model for the $S_{2}$ state as EXAFS results for the $S_{0}, S_{1}$ and $S_{2}$ are all very similar and progression from the $S_{1}$ to the $S_{2}$ state can occur at low temperatures $(<$ $200 \mathrm{~K}$ ), where the protein's conformation should be fixed. The same however cannot be said of the $S_{3}$ state, the last metastable intermediate of the reaction cycle. Recent pulse EPR data has demonstrated that in this state all four Mn ions are structurally and electronically similar: they all exhibit a formal oxidation state 4+ and octahedral local geometry [28]. This requires the inclusion of an additional water-derived ligand at the open coordination site of Mn1 rendering all four Mn ions six-coordinate [28,29]. Importantly the proposed activated structure locates two oxygens $2.4 \AA$ apart along the Mn1-Mn4 axis, the two likely substrates of the water splitting reaction, one of which is $\mathrm{O} 5$ in line with experimental results described above [7,30].

The question arises as to how this structure evolves from the resting state of the catalyst captured using X-ray crystallography. As indicated above the position of O5 is not fixed but toggles between two positions, as an oxygen bridge between Mn3 and $\mathrm{Mn} 4$, as seen in the X-ray structure (A form), and as a vertex of the cubane unit (B form) [9,21] (Fig. 2c). O5 does not display this property in all S-states, but instead evolves towards this dynamic state in the $S_{2}$ state, as it is only in this state that O5 
movement can be coupled with valance isomerism within the cluster $[9,21]$. It is this labile nature of $\mathrm{O} 5$ that provides a possible mechanism via which the solvent inaccessible Mn1 is then connected to the Asp61 water channel described in the previous section (Fig. 4). Briefly, the shift of O5 moves the open coordination site of the cofactor to the solvent accessible $\mathrm{Mn} 4$ [25,31]. This site is then filled by the rotation of the water ligands of Mn4 (W2/W1, $\left.\mathrm{S}_{3}{ }^{\prime}\right)$, with binding of a new water molecule via the Aps61 channel [25]. We note the $\mathrm{Ca}^{2+}$ channel could also provide the new water molecule. Subsequently, the protonation of the two water derived oxygens on the Mn1-Mn4 axis interchanges leading to the final activated catalyst structure $\left(\mathrm{S}_{3}{ }^{\mathrm{A}}\right)$ [32]. Importantly this pathway explains earlier spectroscopic results that suggested the net solvation increases in the $S_{2}$ to $S_{3}$ transition [12,33].

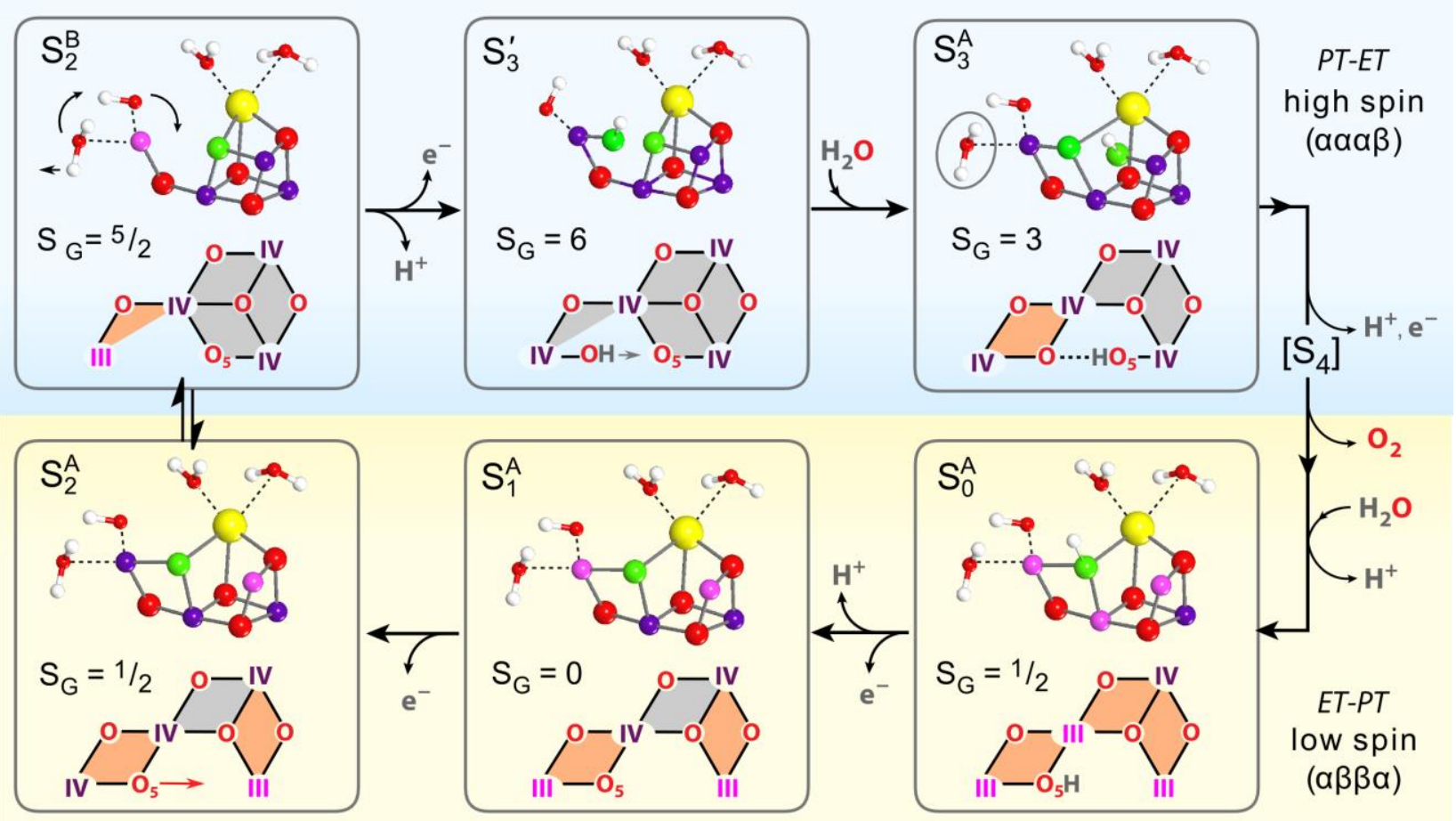

Fig. 4 Self consistent structures of the $\mathrm{Mn}_{4} \mathrm{O}_{5} \mathrm{Ca}$ cofactor during its catalytic cycle developed on the Mülheim campus [5,25,34]. Chemical models shown rationalize many experimental constraints and reproduce all structural and spectroscopic observables. Substrate oxygens are shown in green: O5 and the rotated W2 Mn4 ligand [12,25,34]. $2 D$ electronic coupling maps of the cofactor are shown below each structure, showing how the spin state of the cofactor evolves from low spin configuration in the resting states (dominantly antiferromagnetic coupling between adjacent Mn sites, orange pathways) to high spin configuration in the active states (dominantly ferromagnetic coupling between adjacent Mn sites, grey pathways).

It is likely that the sequential uptake of the substrate waters, with the delayed repositioning of the $2^{\text {nd }}$ substrate, is critical for efficient catalytic function yielding a 
single product. While the sequence described above provides a plausible access pathway for substrate binding/inclusion, the critical question is how this process is regulated. Experimental and theoretical results point to a gating mechanism involving proton shuffling from W1 to the Asp61 [31,35-37], potentially by a rearrangement of the net electric dipole of the cofactor induced by $\mathrm{Y}_{Z}$ oxidation [38]. This redox tuning event then allows cofactor oxidation and subsequently substrate binding to the Mn4, which in the $4+$ oxidation state is a better Lewis acid [25,34]. In this way connections between the conversion of the catalyst from its resting to its active form with the two phases of the catalytic cycle (Figs. 3 and 4) can begin to be made. In the resting-like states (Fig. 4, low panel: $\mathrm{S}_{0}{ }^{\mathrm{A}}, \mathrm{S}_{1}{ }^{\mathrm{A}}, \mathrm{S}_{2}{ }^{\mathrm{A}}$ ) the two putative substrates are kept away from each other and the cofactor is uncoupled from the protein surrounding i.e. ET-PT. In contrast, in the active-like states (Fig. 4, upper panel: $\mathrm{S}_{2}{ }^{\mathrm{B}}, \mathrm{S}_{3}{ }^{\prime}, \mathrm{S}_{3}{ }^{\mathrm{A}}$ ) the two putative substrates are proximal to each other and the cofactor is coupled to the protein surrounding i.e. PT-ET. It is also noted that the two basic forms of the catalyst have a different electronic structure as evidenced by their ground spin state [34]. The resting state forms $\left(\mathrm{S}_{0}{ }^{\mathrm{A}}, \mathrm{S}_{1}{ }^{\mathrm{A}}, \mathrm{S}_{2}{ }^{\mathrm{A}}\right)$ are all low spin whereas the active forms $\left(\mathrm{S}_{2}{ }^{\mathrm{B}}, \mathrm{S}_{3}{ }^{\prime}, \mathrm{S}_{3}{ }^{\mathrm{B}}\right)$ of the catalyst are high spin. The significance of this change in the electronic structure, triggered by the $S_{2}$ to $S_{3}$ water binding step, is not yet understood but is has been suggested as critical for stabilization of the $\mathrm{O}-\mathrm{O}$ bond forming transition state $[28,34]$.

The O-O bond formation step: While recent results described above do not yet constrain the mechanism of water oxidation, they do provide a solid foundation to address this question. Importantly they point towards a mechanism involving the two proximal Mn-bound oxygens, seen in the activated catalyst structure, which are located along the Mn1 and Mn4 axis. There are two popular proposals in the literature explaining how the O-O bond formation could proceed, either by: i) a radical coupling of the two oxygens as proposed by Siegbahn [30] or instead ii) an acid base type reaction involving nucleophilic attack [39]. Current experimental data favor a coupling-type reaction, involving oxidation of one of the substrate oxygens, in part because no $\mathrm{Mn}^{\mathrm{V}}$ intermediate has yet been observed [40]. The challenge though is to devise new experiments to better tease apart the catalytic phase of the cycle (Fig. 3, green area) to conclusively answer this question; namely to address what is the nature of the deprotonation step to form the $\mathrm{S}_{3}{ }^{\mathrm{n}}\left(\mathrm{Y}_{\mathrm{z}}{ }^{\circ}\right)$ state and what is the subsequent fate of this state. This however remains difficult. Obvious routes to capture these 
intermediates, such as using high external $\mathrm{O}_{2}$ pressures do not affect photosynthetic oxygen production [41-43], requiring the equilibrium constant for the $S_{4} \rightarrow S_{0}$ transition to be large $\left(>1.0 \times 10^{7}\right)$ [44]. A more promising approach is to use structurally perturbed systems in which the catalyst activity is diminished [45]. These include site directed mutants (e.g. Asp61, Val185) or replacement of the redoxinactive ions (the exchange of the $\mathrm{Ca}^{2+}$ ion for $\mathrm{Sr}^{2+}$, the $\mathrm{Cl}^{-}$ion(s) for $\mathrm{Br}^{-}$etc) which have been shown to slow the kinetics of O-O bond formation by a factor of up to 100 fold $[46,47]$. This latter approach has allowed water exchange to be studied during the catalytic phase (Fig. 3). Interestingly substrate exchange is arrested in $S_{3}{ }^{n}\left(Y_{Z}{ }^{*}\right)$, favoring a O-O bond mechanism involving substrates that are tightly bound immediately prior to O-O bond formation [47]. This would be consistent with the proposed substrate identities described above i.e. O5 and rotated W2 [12,25,34].

A molecular description of why these structural modifications slow the kinetics of $\mathrm{O}_{2}$ production is not immediately obvious. In these systems the intrinsic $\mathrm{O}-\mathrm{O}$ bond formation step could be slower, or these changes could instead act to retard the advancement of the cofactor through its cycle (Fig. 4), by decoupling cofactor tautomerism from proton release and $2^{\text {nd }}$ substrate inclusion. Clearly further spectroscopic characterizations of these perturbed systems are needed. Of these, new X-ray methods using free electron laser sources have the potential to provide key information, supplementing data already available on the structural and electronic evolution of the native cofactor during the catalysis phase of the cycle [48]. The goal for the future is to determine complete structures of short lived intermediates of the whole catalytic cycle, as free electron laser sources allow diffraction patterns to be collected within femtoseconds of X-ray exposure, providing snapshots of the O-O bond formation step even at ambient temperature $[48,49]$.

Acknowledgement: This work was supported by the Cluster of Excellence RESOLV

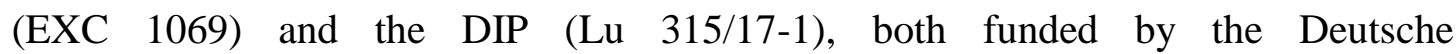
Forschungsgemeinschaft (DFG), and the Bundesministeriums für Bildung und Forschung (BMBF) project MANGAN (03EK3545). 


\section{References:}

**1. Suga M, Akita F, Hirata K, Ueno G, Murakami H, Nakajima Y, Shimizu T, Yamashita K, Yamamoto M, Ago H, Shen J-R: Native structure of photosystem II at 1.95 A resolution viewed by femtosecond $X$-ray pulses. Nature 2015, 517:99-103.

This study reports the first "radiation-damage-free" geometric arrangement of the $\mathrm{Mn}_{4} \mathrm{CaO}_{5}$ cluster in the $\mathrm{S}_{1}$ state. Together with the earlier structure of Umena et al., these data form the basis of our current understanding of the biological water splitting mechanism.

2. Yano J, Yachandra V: Mn4Ca Cluster in Photosynthesis: Where and How Water is Oxidized to Dioxygen. Chemical Reviews 2014, 114:4175-4205.

3. Grundmeier A, Dau H: Structural models of the manganese complex of photosystem II and mechanistic implications. Biochimica et Biophysica Acta (BBA) - Bioenergetics 2012, 1817:88-105.

*4. Beckwith MA, Ames W, Vila FD, Krewald V, Pantazis DA, Mantel C, Pécaut J, Gennari M, Duboc C, Collomb M-N, Yano J, Rehr JJ, Neese F, DeBeer S: How Accurately Can Extended X-ray Absorption Spectra Be Predicted from First Principles? Implications for Modeling the Oxygen-Evolving Complex in Photosystem II. Journal of the American Chemical Society 2015, 137:12815-12834.

This study critically assesses the accuracy and reliability of predicting EXAFS spectra based on quantum chemical calculations.

*5. Krewald V, Retegan M, Cox N, Messinger J, Lubitz W, DeBeer S, Neese F, Pantazis DA: Metal oxidation states in biological water splitting. Chemical Science 2015, 6:1676-1695.

This computational study evaluated an extensive set of models of the biological water splitting cofactor for all stable S-states with respect to all the available experimental data. A single, self-consistent cycle was deduced, based on the high-valent oxidation state model: $\mathrm{S}_{0}$ (III, III, III, IV) $\rightarrow \mathrm{S}_{3}$ (IV, IV, IV, IV).

6. Umena Y, Kawakami K, Shen J-R, Kamiya N: Crystal structure of oxygenevolving photosystem II at a resolution of 1.9 $\AA$. Nature 2011, 473:55-60.

7. Siegbahn PEM: Water oxidation mechanism in photosystem II, including oxidations, proton release pathways, $\mathrm{O}-\mathrm{O}$ bond formation and $\mathrm{O} 2$ release. Biochimica et Biophysica Acta (BBA) - Bioenergetics 2013, 1827:1003-1019.

8. Luber S, Rivalta I, Umena Y, Kawakami K, Shen J-R, Kamiya N, Brudvig GW, Batista VS: S1-State Model of the O2-Evolving Complex of Photosystem II. Biochemistry 2011, 50:6308-6311.

9. Pantazis DA, Ames W, Cox N, Lubitz W, Neese F: Two Interconvertible Structures that Explain the Spectroscopic Properties of the Oxygen 
Evolving Complex of Photosystem II in the $\mathbf{S}_{\mathbf{2}}$ State. Angewandte Chemie International Edition 2012, 51:9935-9940.

10. Koua FHM, Umena Y, Kawakami K, Shen J-R: Structure of Sr-substituted photosystem II at $2.1 \AA$ resolution and its implications in the mechanism of water oxidation. Proceedings of the National Academy of Sciences U.S.A 2013, 110:3889-3894.

11. Cox N, Rapatskiy L, Su J-H, Pantazis DA, Sugiura M, Kulik L, Dorlet P, Rutherford AW, Neese F, Boussac A, Lubitz W, Messinger J: Effect of $\mathrm{Ca}^{2+} / \mathrm{Sr}^{2+}$ substitution on the electronic structure of the oxygen-evolving complex of photosystem II: A combined multifrequency EPR, ${ }^{55} \mathrm{Mn}$ ENDOR, and DFT study of the $\mathbf{S}_{2}$ state. Journal of the American Chemical Society 2011, 133:3635-3648.

12. Cox N, Messinger J: Reflections on substrate water and dioxygen formation. Biochimica et Biophysica Acta (BBA)-Bioenergetics 2013, 1827:1020-1030.

This review compiles all experimental data related to the assignment of the two substrates of the biological water splitting reaction. The conclusion reached by the authors is that $\mathrm{O} 5$ likely represents the early binding substrate water (termed $\mathrm{W}_{\text {slow }}$ ) whereas $\mathrm{W} 2$ represents the late binding/relocated substrate (termed $\mathrm{W}_{\text {fast }}$ ). The labels 'fast' and 'slow' refer to the relative rates with which these two bound substrates exchange with bulk water.

13. Cox N, Pantazis DA, Neese F, Lubitz W: Biological water oxidation. Accounts of chemical research 2013, 46:1588-1596.

*14. Lohmiller T, Krewald V, Navarro MP, Retegan M, Rapatskiy L, Nowaczyk MM, Boussac A, Neese F, Lubitz W, Pantazis DA, Cox N: Structure, ligands and substrate coordination of the oxygen-evolving complex of photosystem II in the $S_{2}$ state: a combined EPR and DFT study. Physical Chemistry Chemical Physics 2014, 16:11877-11892.

In this study the identity of the exchangeable oxygen bridge of the water splitting cofactor was examined by site perturbation, namely the exchange of the $\mathrm{Ca}^{2+}$ ion with $\mathrm{Sr}^{2+}$. This modification leads to a small change in the oxygen bridge signal suggesting the exchangeable bridge is a ligand of the $\mathrm{Ca}^{2+}$, most likely O5. This study also restricts the number of exchangeable bridges to be only one.

*15. Pérez-Navarro M, Ames WM, Nilsson H, Lohmiller T, Pantazis DA, Rapatskiy L, Nowaczyk MM, Neese F, Boussac A, Messinger J, Lubitz W, Cox N: Ammonia binding to the oxygen-evolving complex of photosystem II identifies the solvent-exchangeable oxygen bridge ( $\boldsymbol{\mu}$-oxo) of the manganese tetramer. Proceedings of the National Academy of Sciences U.S.A 2013, 110:15561-15566.

This EPR, DFT and time-resolved membrane inlet mass spectrometry study examined the binding of ammonia to the water splitting cofactor. It was observed that ammonia likely displaces the water (W1) ligand of Mn4. As ammonia binding simultaneously 
has a large effect on the exchangeable oxygen bridge, it was deduced that this bridge must be located trans to its binding position i.e. trans to $\mathrm{W} 1$, the $\mathrm{O} 5$ position.

16. Rapatskiy L, Cox N, Savitsky A, Ames WM, Sander J, Nowaczyk MM, Rögner M, Boussac A, Neese F, Messinger J: Detection of the water-binding sites of the oxygen-evolving complex of photosystem II using $\mathrm{W}$-band ${ }^{17} \mathrm{O}$ electron-electron double resonance-detected NMR spectroscopy. Journal of the American Chemical Society 2012, 134:16619-16634.

17. McConnell IL, Grigoryants VM, Scholes CP, Myers WK, Chen P-Y, Whittaker JW, Brudvig GW: EPR-ENDOR Characterization of $\left({ }^{17} \mathrm{O},{ }^{1} \mathbf{H},{ }^{2} \mathbf{H}\right)$ Water in Manganese Catalase and Its Relevance to the Oxygen-Evolving Complex of Photosystem II. Journal of the American Chemical Society 2012, 134:1504-1512.

18. Siegbahn PEM: Substrate Water Exchange for the Oxygen Evolving Complex in PSII in the S1, S2, and S3 States. Journal of the American Chemical Society 2013, 135:9442-9449.

19. Rapatskiy L, Ames WM, Perez-Navarro M, Savitsky A, Griese JJ, Weyhermüller T, Shafaat HS, Högbom M, Neese F, Pantazis DA, Cox N: Characterization of Oxygen Bridged Manganese Model Complexes Using Multifrequency ${ }^{17}$ O-Hyperfine EPR Spectroscopies and Density Functional Theory. The Journal of Physical Chemistry B 2015.

20. Nilsson H, Krupnik T, Kargul J, Messinger J: Substrate water exchange in photosystem II core complexes of the extremophilic red alga Cyanidioschyzon merolae. Biochimica et Biophysica Acta (BBA) Bioenergetics 2014, 1837:1257-1262.

21. Bovi D, Narzi D, Guidoni L: The $\mathbf{S}_{2}$ State of the Oxygen Evolving Complex of Photosystem II Explored by QM/MM Dynamics: Spin Surfaces and Metastable States Suggest a Reaction Path Towards the S3 State. Angewandte Chemie International Edition 2013, 52:11744-11749.

22. Schraut J, Kaupp M: On Ammonia Binding to the Oxygen-Evolving Complex of Photosystem II: A Quantum Chemical Study. Chemistry - A European Journal 2014, 20:7300-7308.

23. Oyala PH, Stich TA, Debus RJ, Britt RD: Ammonia Binds to the Dangler Manganese of the Photosystem II Oxygen-Evolving Complex. Journal of the American Chemical Society 2015, 137:8829-8837.

24. Oyala PH, Stich TA, Stull JA, Yu F, Pecoraro VL, Britt RD: Pulse Electron Paramagnetic Resonance Studies of the Interaction of Methanol with the $\mathrm{S}_{\mathbf{2}}$ State of the $\mathrm{Mn}_{4} \mathrm{O}_{5}$ Ca Cluster of Photosystem II. Biochemistry 2014, 53:7914-7928.

**25. Retegan M, Krewald V, Mamedov F, Neese F, Lubitz W, Cox N, Pantazis DA: A five-coordinate $\mathrm{Mn}(\mathrm{IV})$ intermediate in biological water oxidation: spectroscopic signature and a pivot mechanism for water binding. Chemical Science 2016, 7:72-84.

This study conclusively demonstrates that ammonia displaces the W1 ligand of Mn4. It is shown that mutation of the Asp61 residue, which provides a hydrogen bond to $\mathrm{W} 1$, perturbs the bound ammonia signal requiring ammonia to bind at the $\mathrm{W} 1$ site. 
26. Klauss A, Haumann M, Dau H: Alternating electron and proton transfer steps in photosynthetic water oxidation. Proceedings of the National Academy of Sciences 2012, 109:16035-16040.

*27. Klauss A, Haumann M, Dau H: Seven Steps of Alternating Electron and Proton Transfer in Photosystem II Water Oxidation Traced by TimeResolved Photothermal Beam Deflection at Improved Sensitivity. The Journal of Physical Chemistry B 2015, 119:2677-2689.

Using a new spectroscopic technique, Time-Resolved Photothermal Beam Deflection, the authors were able to identify seven discrete transitions within the S-state cycle.

These steps provide important information on the sequence of the alternate between electron transfer and charge-compensating proton transfer events that occur during the cycle.

**28. Cox N, Retegan M, Neese F, Pantazis DA, Boussac A, Lubitz W: Electronic structure of the oxygen-evolving complex in photosystem II prior to $\mathrm{O}-\mathrm{O}$ bond formation. Science 2014, 345:804-808.

As described in the main text, this study demonstrates that the stoichiometry of the biological water splitting cofactor changes in the final metastable intermediate state of the cycle $\left(S_{3}\right)$. These results require that the $S_{2}$ to $S_{3}$ transition involves a water binding event.

29. Li X, Siegbahn PE, Ryde U: Simulation of the isotropic EXAFS spectra for the $S_{2}$ and $S_{3}$ structures of the oxygen evolving complex in photosystem II. Proceedings of the National Academy of Sciences 2015, 112:3979-3984.

30. Li X, Siegbahn PEM: Alternative mechanisms for $\mathrm{O}_{2}$ release and $\mathrm{O}-\mathrm{O}$ bond formation in the oxygen evolving complex of photosystem II. Physical Chemistry Chemical Physics 2015, 17:12168-12174.

*31. Narzi D, Bovi D, Guidoni L: Pathway for Mn-cluster oxidation by tyrosine-Z in the $\mathbf{S}_{\mathbf{2}}$ state of photosystem II. Proceedings of the National Academy of Sciences 2014, 111:8723-8728.

This QM/MM study examines the initial phase of the $S_{2}$ to $S_{3}$ transition. The authors demonstrate that cofactor oxidation is triggered by proton shuffling between the Asp61 and W1, suggesting Asp61 participates in a proton egress pathway, as had been proposed earlier from experiment. Importantly, oxidation of the cofactor is seen only for the closed $\left(\mathrm{S}_{2}{ }^{\mathrm{B}}\right)$ state, not the open $\left(\mathrm{S}_{2}{ }^{\mathrm{A}}\right)$ state.

*32. Capone M, Bovi D, Narzi D, Guidoni L: Reorganization of substrate waters between the closed and open cubane conformers during the $S_{2}$ to $S_{3}$ transition in the Oxygen Evolving Complex. Biochemistry 2015.

This very recent study examined the putative final rearrangement step in the $S_{2}$ to $S_{3}$ transition, which occurs after cofactor deprotonation, oxidation and water binding. The authors propose a novel mechanism allowing downhill conversion from a closed 
type intermediate structure $\left(S_{3}{ }^{B}\right)$ to the experimentally observed open type structure $\left(\mathrm{S}_{3}{ }^{\mathrm{A}}\right)$.

33. Noguchi T: FTIR detection of water reactions in the oxygen-evolving centre of photosystem II. Philosophical Transactions of the Royal Society of London B: Biological Sciences 2008, 363:1189-1195.

34. Krewald V, Retegan M, Neese F, Lubitz W, Pantazis DA, Cox N: Spin State as a Marker for the Structural Evolution of Nature's Water-Splitting Catalyst. Inorganic Chemistry 2015.

35. Debus RJ: Evidence from FTIR Difference Spectroscopy That D1-Asp61 Influences the Water Reactions of the Oxygen-Evolving $\mathrm{Mn}_{4} \mathrm{CaO}_{5}$ Cluster of Photosystem II. Biochemistry 2014, 53:2941-2955.

36. Siegbahn PEM: Mechanisms for proton release during water oxidation in the $S_{2}$ to $S_{3}$ and $S_{3}$ to $S_{4}$ transitions in photosystem II. Physical Chemistry Chemical Physics 2012, 14:4849-4856.

37. Rivalta I, Amin M, Luber S, Vassiliev S, Pokhrel R, Umena Y, Kawakami K, Shen J-R, Kamiya N, Bruce D, Brudvig GW, Gunner MR, Batista VS: Structural-Functional Role of Chloride in Photosystem II. Biochemistry 2011, 50:6312-6315.

38. Retegan M, Cox N, Lubitz W, Neese F, Pantazis DA: The first tyrosyl radical intermediate formed in the $\mathbf{S}_{2}-\mathbf{S}_{3}$ transition of photosystem II. Physical Chemistry Chemical Physics 2014, 16:11901-11910.

39. Sproviero EM, Gasc $\tilde{A}^{3} n$ JA, McEvoy JP, Brudvig GW, Batista VS: Quantum Mechanics/Molecular Mechanics Study of the Catalytic Cycle of Water Splitting in Photosystem II. Journal of the American Chemical Society 2008, 130:3428-3442.

40. Haumann M, Liebisch P, Müller C, Barra M, Grabolle M, Dau H: Photosynthetic $\mathrm{O}_{2}$ Formation Tracked by Time-Resolved X-ray Experiments. Science 2005, 310:1019-1021.

41. Haumann M, Grundmeier A, Zaharieva I, Dau H: Photosynthetic water oxidation at elevated dioxygen partial pressure monitored by timeresolved X-ray absorption measurements. Proceedings of the National Academy of Sciences 2008, 105:17384-17389.

42. Kolling DRJ, Brown TS, Ananyev G, Dismukes GC: Photosynthetic Oxygen Evolution Is Not Reversed at High Oxygen Pressures: Mechanistic Consequences for the Water-Oxidizing Complex. Biochemistry 2009, 48:1381-1389.

43. Shevela D, Beckmann K, Clausen J, Junge W, Messinger J: Membrane-inlet mass spectrometry reveals a high driving force for oxygen production by photosystem II. Proceedings of the National Academy of Sciences 2011, 108:3602-3607.

44. Nilsson H, Cournac L, Rappaport F, Messinger J, Lavergne J: Estimation of the driving force for dioxygen formation in photosynthesis. Biochimica et Biophysica Acta (BBA)-Bioenergetics 2016, 1857:23-33.

45. Boussac A, Rutherford AW, Sugiura M: Electron transfer pathways from the $\mathrm{S}_{2}$-states to the $\mathrm{S}_{3}$-states either after a $\mathrm{Ca}^{2+} / \mathrm{Sr}^{2+}$ or a $\mathrm{Cl}^{-} / \mathrm{I}^{-}$exchange in Photosystem II from Thermosynechococcus elongatus. Biochimica et Biophysica Acta (BBA)-Bioenergetics 2015, 1847:576-586. 
46. Bao H, Burnap RL: Structural rearrangements preceding dioxygen formation by the water oxidation complex of photosystem II. Proceedings of the National Academy of Sciences U.S.A 2015:201512008.

**47. Nilsson H, Rappaport F, Boussac A, Messinger J: Substrate-water exchange in photosystem II is arrested before dioxygen formation. Nature communications 2014, 5.

This study used time-resolved membrane inlet mass spectrometry to study the rate of exchange of the two substrate waters immediately prior to the $\mathrm{O}-\mathrm{O}$ bond formation step. This experiment could only be achieved using chemically modified versions of the cofactor. The authors observe no exchange in this intermediate state $\left(\mathrm{S}_{3}{ }^{\mathrm{n}} \mathrm{Y}_{\mathrm{Z}}{ }^{*}\right)$

suggesting the two substrates are tightly bound. From this result the authors favor the two substrates being Mn ligated oxygen sites (O5 and W2).

48. Kern J, Tran R, Alonso-Mori R, Koroidov S, Echols N, Hattne J, Ibrahim M, Gul S, Laksmono H, Sierra RG, et al.: Taking snapshots of photosynthetic water oxidation using femtosecond $\mathrm{X}$-ray diffraction and spectroscopy. Nat Commun 2014, 5.

49. Kupitz C, Basu S, Grotjohann I, Fromme R, Zatsepin NA, Rendek KN, Hunter MS, Shoeman RL, White TA, Wang D, et al.: Serial time-resolved crystallography of photosystem II using a femtosecond $\mathrm{X}$-ray laser. Nature 2014, 513:261-265. 